\title{
Evaluation of Different Leaf Litters for Oyster Mushroom (Pleurotus Ostreatus) Cultivation in Nekemte City, Western Ethiopia
}

\author{
Tadesse Gelano ${ }^{1}$ Diriba Muleta ${ }^{2}$ Mebrate Dufera ${ }^{3 *}$ \\ 1.Department of Biology, Nekemte Preparatory School, Nekemte, Ethiopia \\ 2.Department of Microbial, Cellular and Molecular Biology, Addis Ababa University, Post Bo No: 1176, Addis \\ Ababa, Ethiopia \\ 3.Department of Biology, Wollega University, Post Box No: 395, Nekemte, Ethiopia
}

\begin{abstract}
Cultivation of mushrooms using locally available substance is a very cheap and environmentally friendly alternative for producing foods with high nutritional value. The consumption and familiarity of mushrooms to people has been limited in Ethiopia largely due to poor knowledge on the methods of production. The aim of this study was to evaluate different locally available leaf litters and their combinations for their productivity and biological efficiency (BE) for cultivation of an edible mushroom strain, oyster (Pleurotus ostreatus); in Nekemte, east Wollega, Ethiopia between January, 2017 and September, 2017. An experiment was conducted to cultivate edible mushroom (Pleurotus ostreatus) using four different leaf litters: namely,Cordia africana, Croton macrostachyus,Catha edulis and Eucalyptus camaldulensis and their combinations to determine their biological efficiency for the selected mushroom species. The results showed that, mycelial extension, the highest and lowest mean value $0.521 \mathrm{~cm} /$ day and $0.323 \mathrm{~cm}$ were measured from Catha edulis and combination of Catha edulis, Croton macrostachyus and Cordia africana, respectively. The results revealed that differences in mean incubation periods and duration of pinning-to-maturation, pileus diameter, and stipe length were insignificant $(\mathrm{p}>0.05)$ among substrates. The first pinning took 34.66 days, followed by 9.66 to 10.66 days between different flushes. Mean durations from pinning-to-maturation ranged from 3.66 to 4.33 days. The mean pileus diameter of mushrooms ranged from 4.77 to $5.03 \mathrm{~cm}$, whereas the mean stipe length ranged from 1.98 to $2.16 \mathrm{~cm}$. In this study, the highest biological efficiency for the studied mushroom species was recorded from Croton macrostachyus leaf litter $((94.45 \%)$ followed by Eucalpytus camaldulis leaf litters $(89.72 \%)$. All the substrates that gave over $50 \%$ BE could be recommended for oyster mushroom cultivation. The findings generally suggest that the mushrooms species when grown on locally available leaf litters may have the potential to solve the problem of food insecurity in Ethiopia and can also create job opportunity to youngsters.
\end{abstract}

Keywords: Biological efficiency, Edible mushrooms, Spawn, Substrates

DOI: $10.7176 / \mathrm{JNSR} / 11-13-05$

Publication date:July $31^{\text {st }} 2020$

\section{Introduction}

One of the world's biggest challenges is food insecurity. This problem is largely common in low and middleincome countries that mainly have poor food production systems and suffer from serious malnutrition. Such countries must find ways of improving food production to feed the vastly increasing human population (Gume et al., 2013) and mushroom cultivation could be a possible option to alleviate poverty and develop the life style of the vulnerable people. Mushrooms include edible, medicinal and poisonous species and are nature's gift as they are protein rich foods for human beings. They are fleshy, spore bearing reproductive structures of fungi. For a long time, wild edible mushrooms have played an important role as a human food (Chang and Miles, 2004).

Mushroom cultivation offers benefit, when it is integrated into the existing production system by producing nutritious food at a profit, while using materials that would otherwise be considered "waste" (Beteez and Kustudia, 2004). Due to their nutritional, medicinal and ecological advantages, mushrooms have attracted the attention of many people in the world (Imtiaj and Rahman, 2008). Cultivation of edible mushrooms may be the only available biotechnology for lignocellulosic organic waste recycling that combines the production of protein rich food with the reduction of environmental pollution (Beteez and Kustudia, 2004). Mushrooms cultivation and consumption culture is more developed in China, Japan, Korea, Thailand, America (Feeney and Beelman, 2004). Although least known in Africa, countries like Nigeria, Egypt, Kenya, Zimbabwe, and South Africa are relatively making good trials. Despite the high diversity of wild edible mushrooms in Africa including Ethiopia, very little of it is known. Cultivation of mushrooms has not practiced on commercial scales in most developing countries and has consequently affected commercial mushroom marketing, which is yet to be embraced by most farmers (Abate, 1998).

In Ethiopia, mushroom cultivation is a very recent activity with almost no mushroom consumption and cultivation techniques known except for few trials in small-scale production of Agarics bisporus, Lentinus edodes, 
and Pleurotus species (Abate, 1998).

Oyster mushrooms are one of the most popular edible mushrooms and belong to the genus Pleurotus and the family Pleurotaceae. Many of the Pleurotus mushrooms are primary decomposers of hardwood trees and are found worldwide. Two decades back, approximately about 70 species of Pleurotus had recorded and new species were subsequently discovered more or less frequently although some of them were considered identical with previously recognized species (Badshah et al., 1992). The oyster mushrooms can be cultivated successfully under semicontrolled conditions in a small space by using agricultural as well as industrial wastes and other refuse as substrate (Singh and Singh, 2005).

Edible mushroom production is one of the ways to alleviate the existing problem. Although there are abundant amounts of agricultural wastes and leaf litters and suitable prevailing temperature in western parts of Ethiopia for cultivation of edible mushrooms, there is no published information regarding cultivation of mushrooms in and around Nekemte. The current study was therefore, initiated to assess the possibility and amount of yield from mushroom cultivation on locally available substrates.

\section{Materials and Methods \\ Description of the study area}

The study was conducted in Nekemte City at Wollega University from January 2017 to September 2017. The town is located at $331 \mathrm{~km}$ west of Addis Ababa. Nekemte is the capital city of east Wollega Zone, Oromia Regional State, west Ethiopia. It is located at $9^{\circ} 5^{\prime} \mathrm{N}$ and $36^{\circ} 33^{\prime} \mathrm{E}$ with altitude of ranging $1300-1340 \mathrm{~m}$ above sea level within dega climatic classification. The area has annual average temperature of $20^{\circ} \mathrm{C}$ and mean annual rainfall of $2150 \mathrm{~mm}$.

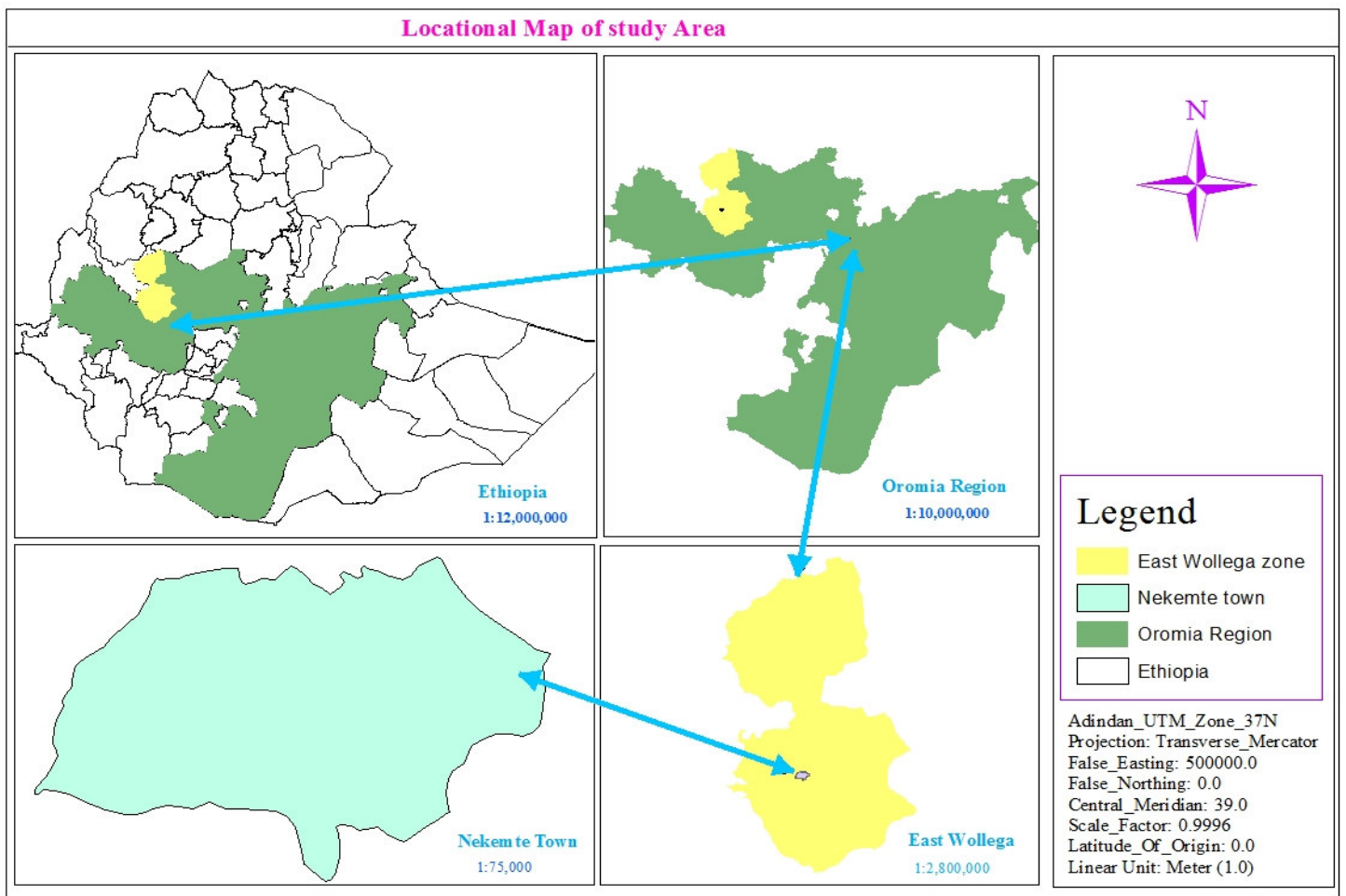

Figure 1. Map of the study area. (Source: Oromia urban institute western branch office, 2018)

\section{Mushroom growing room}

Aseptic room $160 \mathrm{~cm}$ by $320 \mathrm{~cm}$ was prepared at Wollega University, Biology Department Research Laboratory ahead of time by washing the walls, the sealing and the floor using detergent (savlon). Shelves were set in the room that accommodated 45 treatment bags. Windows were closed and covered with thick cartoons to create dark environment for incubation of mushroom bags.

\section{Culture source and culture transfer}

The Culture of Pleurotus ostreatus (Oyster mushroom) was obtained from the Mycology Laboratory, Department of Biology, Addis Ababa University, Addis Ababa, Ethiopia. The pure culture of Pleurotus ostreatus was transferred to potato dextrose agar (PDA) plates and slants. The plate subcultures were stored at room temperature $\left(22 \pm 2{ }^{\circ} \mathrm{C}\right)$ for 7 days. The slants were kept in a refrigerator at $4 \pm 2{ }^{\circ} \mathrm{C}$. Non-contaminated plate cultures were directly used for the spawn preparation. The contents in the contaminated plates were removed after steam 
sterilization.

\section{Spawn preparation}

Following the method used by Gume et al. (2013), in this study, the spawn (mushroom seed) of Pleurotus ostreatus was produced on sorghum grain $(95 \%)$ and shredded wheat $(5 \%)$. The required amount of clean sorghum grains were weighed and soaked overnight in a sufficient amount of water. After the grains imbibed and reached $60 \%$ moisture (i.e. rose to $60 \%$ weight), the grains were mixed with $5 \%$ shredded wheat and $1 \%$ gypsum and packaged (leaving air space) in different glass jars of 300-500 $\mathrm{ml}$ volume. The packaged content was then steam sterilized in autoclave at 15 psi for one hour. After cooling, the jars containing sterile sorghum grains were inoculated aseptically by transferring approximately $1 \mathrm{~cm}^{2}$ of fungal blocks from plate culture by slicing into pieces using sterile scalpels under laminar flow hood. Thereafter, each jar was kept at room temperature $\left(22 \pm 2{ }^{\circ} \mathrm{C}\right)$ and was inspected until the grains had been fully colonized by mycelia and the spawn turn white (cottony) in the jars. The jars were shaken in the $3^{\text {rd }}$ and $8^{\text {th }}$ days to hasten through invasion of the grains by mycelia. Contaminations were inspected at five days interval.

\section{Main substrates}

Four different types of main substrates, namely leaf litters of Cordia Africana, Croton macrostachyus, Eucalyptus camaldulensis and Catha edulis were used. Cordia africana and Croton macrostachyus leaf litters were collected from Nekemte preparatory School campus. The Eucalyptus camaldulensis leaf litters were collected from Burka Jato Sub City in Nekemte City. The Catha edulis leaf litters were collected from khat vending houses

\section{Substrate preparation and combination}

The leaf liters were mechanically chopped manually, into small pieces using hammer mill. Leaf litters of Cordia africana, Croton macrostachyus, Eucalyptus camaldulensis and Catha edulis were used separately as well as in combination as substrate. Equal amounts of substrates were combined in many ways. The substrates were paired and combined with each pair representing 50\% (200 g: $200 \mathrm{~g})$ by weight. Again they were combined in three each representing 33.33\% (133.33 g: $133.33 \mathrm{~g}: 133.33 \mathrm{~g}$ ) by weight. Further, the substrates were combined by four where each represented 25\% (100 g: $100 \mathrm{~g}: 100 \mathrm{~g}: 100 \mathrm{~g}$ ) by weight. To about $80 \%$ of each substrate, $10 \%$ of cow dung, $8 \%$ of shredded wheat and $2 \%$ wood ash were added on dry weight basis (Alemu, 2014).

\section{Substrate sterilization and cultivation of mushroom}

The substrates were put into plastic bags of $20 \times 30 \mathrm{~cm}$ size at the rate of $400 \mathrm{~g}$ main substrate in triplicate. Each bag was labeled according to substrate they contain and autoclaved at 15 psi for 1 hour and kept in laminar flow hood until they cooled down. There were 45 treatments (triplets of the four substrates and their different combinations). The transparent polyethylene bags were sterilized by immersing into $75 \%$ ethanol and washed with sterile distilled water. A $40 \mathrm{~g}$ (10\% of the substrate) of Pleurotus ostreatus spawn was aseptically added into the polyethylene bags using sterile spoons inside laminar flow hood. This percentage of spawn is nearly an average of $1-20 \%$ amount complained as "uneconomical" (20\%) and "under spawning" (1\%) by Kivaisi (2007). Following the method described in Mush World (2005), the $1^{\text {st }}$ and the $2^{\text {nd }}$ replicate bags were spawned by localized spawning at the open end and at three locations (top, middle and bottom), respectively. The $3^{\text {rd }}$ replicate bag was spawned throughout by mixing of the spawn into the substrate. Then the open end of the bags was tied using rubber bands and small numbers of holes were made using sterile needle to allow air exchange in bags. Finally, all the bags were incubated on shelves in a completely randomized design.

\section{Incubation and control of the environment}

All the inoculated bags were incubated in a complete darkness. Fresh air exchange between the dark room and the outside environment was allowed by opening windows at night. Plastic containers were filled with water and placed open at every corner of the dark room to maintain appropriate humidity in the room for the mycelia growth. In addition, water was sprayed manually on the walls. This condition can maintain approximately $70-80 \%$ humidity as suggested by Oei (2005). After 20 days of incubation, close observation of the bags were made to recognize complete spawn run and primordial formation.

\section{Mycelia growth measurement}

The treatment bags were inspected on weekly basis for appropriate mycelia growth and contamination (if any). Generally, mycelium running is an extension and colonization of fungal hypha throughout the leaf litter. Mycelia extension through the substrates in the treatment bags were measured using transparent graduated ruler following the method used by Rajapakse et al. (2007) and the data were recorded. 


\section{Induction of fruiting}

After the incubation period, when the bags were completely colonized by the mycelium, the bags were opened to induce formation of fruit bodies (Kivaisi, 2007). Holes (approximately $2 \mathrm{~cm}$ in diameter) were made in the sides of bags to allow pinheads to emerge. The bags were watered three times a day.

\section{Harvesting and yield measuring}

Mature mushrooms were picked by hand without harming the substrate when they started to wrinkle-ripe. This was done for four consecutive flushes. For incubation between flushes, the bags were not watered for 5 days. Following the method of Iqbal et al. (2005), the yield parameters were recorded with respect to time (days) taken for completion of spawn running, time taken for the first appearance of pinhead formation, time taken for maturity of fruit bodies, number of flushes, time interval between flushes and yield of flushes for the treatment substrates. The pileus diameter and the stipe length were measured with graduated transparent ruler following the method of Onuoha et al. (2009). Mature mushrooms were weighed with beam balance to determine the biological efficiency and quality of mushrooms produced from the substrates. The average bioconversion efficiency of harvests was computed according to the following formula (Peng et al., 2000).

$$
\mathrm{BE}=\frac{\text { Weight of fresh mushroom harvested }}{\text { Dry weight of substrate before inoculation }} \times 100
$$

\section{Data analysis}

Data were analyzed statistically on the basis of substrate and yield per flush and of total flush using SPSS window version 20.0, SPSS Inc, Chicago, IL, USA. Analysis of Variance (ANOVA) was used to indicate the significant differences between mean values at $95 \%$ confidence interval. Effect of leaf litters on yield parameter of mushroom was compared with LSD test.

\section{Results}

The oyster mushroom completely covered the Petri dishes in 7 days on PDA media. It appeared cottony in color (Figure 2a). Once a pure culture of mushroom is obtained, the spawn could be made from it. Fully white mycelia invasion of Pleurotus ostreatus was observed on sorghum after 21-25 days of incubation (Figure 2b) and was ready to be used for the inoculation of the solid substrate.

Different bags were used to evaluate mycelium extension using different locally available leaf litters (Table1). There were significant $(\mathrm{P}<0.05)$ differences in the mycelial extension of oyster mushroom grown on different substrates. Accordingly, Catha edulis (Ce) showed the fastest mycelial extension followed by Eucalpytus camaldulis (Ec). However, combination of Catha edulis, Croton macrostachyus and Cordia africana $(\mathrm{CeCmCa})$ exhibited the lowest mycelial extension. The mean values of mycelial extension $(\mathrm{cm} /$ day) were found proportional to the mycelia extension on $7^{\text {th }}$ and $14^{\text {th }}$ days. There were significant $(p<0.05)$ differences in the days required for complete colonization of the leaf litters that received different treatments with the lowest and the highest days being 23.00 and 37.33 days, respectively. The highest running rate in length was observed in Catha edulis (Ce) ( $7.30 \mathrm{~cm}$ on 14 days) followed by Eucalpytus camaldulis $(\mathrm{Ec})(7.20 \mathrm{~cm}$ on 14 days).The lowest running rate in length of mycelium was observed in,combination of Catha edulis, Croton macrostachyus and Cordia africana $(\mathrm{CeCmCa})(4.53 \mathrm{~cm}$ on 14 days). According to this result, the highest average day required for the complete colonization was 37.33 days. 
Table 1. Mycelial extension corresponding to substrate treatments

\begin{tabular}{|c|c|c|c|c|}
\hline \multirow[t]{2}{*}{ Leaf litters (substrates) } & \multicolumn{2}{|c|}{ Mycelium extension } & \multirow{2}{*}{$\begin{array}{l}\text { Mean }(\mathrm{cm} / \text { day }) \\
(\mathrm{MRR})\end{array}$} & \multirow{2}{*}{$\begin{array}{l}\text { Total days required for } \\
\text { complete colonization }\end{array}$} \\
\hline & 7 days & 14 days & & \\
\hline Ec & $3.53^{\mathrm{a}}$ & $7.20^{\mathrm{a}}$ & $0.513^{\mathrm{a}}$ & $23.33^{\mathrm{c}}$ \\
\hline $\mathrm{Ce}$ & $3.53^{\mathrm{a}}$ & $7.30^{\mathrm{a}}$ & $0.521^{\mathrm{a}}$ & $23.00^{c}$ \\
\hline $\mathrm{Cm}$ & $2.53^{\mathrm{b}}$ & $5.33^{\mathrm{c}}$ & $0.380^{c}$ & $32.00^{\mathrm{b}}$ \\
\hline $\mathrm{Ca}$ & $2.36^{\mathrm{ab}}$ & $5.06^{\mathrm{c}}$ & $0.361^{\mathrm{c}}$ & $33.00^{\mathrm{b}}$ \\
\hline $\mathrm{EcCe}$ & $2.00^{\mathrm{ab}}$ & $5.10^{\mathrm{c}}$ & $0.370^{\mathrm{c}}$ & $32.66^{\mathrm{b}}$ \\
\hline $\mathrm{EcCm}$ & $2.00^{\mathrm{ab}}$ & $5.00^{c}$ & $0.356^{\mathrm{c}}$ & $33.33^{\mathrm{b}}$ \\
\hline $\mathrm{EcCa}$ & $2.36^{\mathrm{ab}}$ & $4.96^{\mathrm{cd}}$ & $0.354^{\mathrm{c}}$ & $33.66^{\mathrm{b}}$ \\
\hline $\mathrm{CeCm}$ & $2.26^{\mathrm{ab}}$ & $4.90^{\mathrm{cd}}$ & $0.349^{c}$ & $34.00^{\mathrm{b}}$ \\
\hline $\mathrm{CmCa}$ & $2.33^{\mathrm{ab}}$ & $4.83^{\mathrm{cd}}$ & $0.345^{\mathrm{c}}$ & $34.33^{\mathrm{b}}$ \\
\hline $\mathrm{CeCa}$ & $2.50^{\mathrm{b}}$ & $5.06^{\mathrm{c}}$ & $0.359^{\mathrm{c}}$ & $33.33^{\mathrm{b}}$ \\
\hline $\mathrm{EcCeCm}$ & $2.50^{\mathrm{b}}$ & $5.10^{\mathrm{c}}$ & $0.364^{\mathrm{c}}$ & $32.66^{\mathrm{b}}$ \\
\hline $\mathrm{EcCeCa}$ & $2.43^{\mathrm{ab}}$ & $4.93^{\mathrm{cd}}$ & $0.352^{\mathrm{c}}$ & $33.66^{\mathrm{b}}$ \\
\hline $\mathrm{CeCmCa}$ & $2.20^{\mathrm{ab}}$ & $4.53^{\mathrm{cd}}$ & $0.323^{\mathrm{ac}}$ & $37.33^{\mathrm{a}}$ \\
\hline $\mathrm{EcCmCa}$ & $2.40^{\mathrm{ab}}$ & $5.00^{\mathrm{c}}$ & $0.356^{\mathrm{c}}$ & $33.66^{\mathrm{b}}$ \\
\hline $\mathrm{EcCeCmCa}$ & $2.63^{\mathrm{b}}$ & $5.40^{\mathrm{c}}$ & $0.385^{\mathrm{c}}$ & $31.00^{\mathrm{ab}}$ \\
\hline$\% \mathrm{CV}$ & 18.08 & 15.27 & 15.24 & 12.04 \\
\hline
\end{tabular}

Key: Eucalpytus camaldulis (Ec), Catha edulis (Ce), Croton macrostachyus (Cm), Cordia africana (Ca); EcCe (combination of $\mathrm{Ec}$ and $\mathrm{Ce}$ ), EcCm (combination of $\mathrm{Ec}$ and $\mathrm{Cm}$ ), EcCa (combination of Ec and $\mathrm{Ca}$ ), $\mathrm{CeCm}$ (combination of $\mathrm{Ce}$ and $\mathrm{Cm}$ ), $\mathrm{CmCa}$ (combination of $\mathrm{Cm}$ and $\mathrm{Ca}$ ), $\mathrm{CeCa}$ (combination of CeCa), $\mathrm{EcCeCm}$ (combination of $\mathrm{Ec}, \mathrm{Ce}$ and $\mathrm{Cm}$ ), $\mathrm{EcCeCa}$ (combination of $\mathrm{Ec}, \mathrm{Ce}$ and $\mathrm{Ca}$ ), CeCmCa (combination of Ce,Cm and $\mathrm{Ca}$ ), EcCmCa (combination of $\mathrm{Ec}, \mathrm{Cm}$ and $\mathrm{Ca}$ ) and $\mathrm{EcCeCmCa}$ (combination of Ec, Ce, Cm and Ca).

Mean values within a column with the same superscript letter(s) are not significantly different ( $p>0.05)$.

The leaf litters of Catha edulis (Ce), showed shorter incubation periods (34.66 days) followed by Eucalpytus camaldulis (Ec) (35 days). Longer incubation period (47.00 days) was recorded for combination of Croton macrostachyus and Cordia africana $(\mathrm{CmCa})$. Mean incubation periods of mushroom flushes showed highly significant $(\mathrm{p}<0.05)$ differences). Greater than $10 \% \mathrm{CV}$ indicates high variation in mean values of incubation periods.

Table 2. Incubation periods of leaf litters used as substrate

\begin{tabular}{|c|c|c|c|c|c|}
\hline \multirow{2}{*}{$\begin{array}{l}\text { Leaf } \\
\text { (substrates) }\end{array}$} & \multirow[t]{2}{*}{ litters } & \multicolumn{2}{|c|}{ Mycelium extension } & \multirow{2}{*}{$\begin{array}{l}\text { Mean (cm/day) } \\
(\text { MRR) }\end{array}$} & \multirow{2}{*}{$\begin{array}{l}\text { Total days required for } \\
\text { complete colonization }\end{array}$} \\
\hline & & 7 days & 14 days & & \\
\hline Ec & & $3.53^{\mathrm{a}}$ & $7.20^{\mathrm{a}}$ & $0.513^{\mathrm{a}}$ & $23.33^{\mathrm{c}}$ \\
\hline $\mathrm{Ce}$ & & $3.53^{\mathrm{a}}$ & $7.30^{\mathrm{a}}$ & $0.521^{\mathrm{a}}$ & $23.00^{\mathrm{c}}$ \\
\hline $\mathrm{Cm}$ & & $2.53^{\mathrm{b}}$ & $5.33^{\mathrm{c}}$ & $0.380^{c}$ & $32.00^{\mathrm{b}}$ \\
\hline $\mathrm{Ca}$ & & $2.36^{\mathrm{ab}}$ & $5.06^{\mathrm{c}}$ & $0.361^{\mathrm{c}}$ & $33.00^{\mathrm{b}}$ \\
\hline $\mathrm{EcCe}$ & & $2.00^{\mathrm{ab}}$ & $5.10^{\mathrm{c}}$ & $0.370^{c}$ & $32.66^{\mathrm{b}}$ \\
\hline $\mathrm{EcCm}$ & & $2.00^{\mathrm{ab}}$ & $5.00^{\mathrm{c}}$ & $0.356^{\mathrm{c}}$ & $33.33^{\mathrm{b}}$ \\
\hline $\mathrm{EcCa}$ & & $2.36^{\mathrm{ab}}$ & $4.96^{\mathrm{cd}}$ & $0.354^{\mathrm{c}}$ & $33.66^{\mathrm{b}}$ \\
\hline $\mathrm{CeCm}$ & & $2.26^{\mathrm{ab}}$ & $4.90^{\mathrm{cd}}$ & $0.349^{c}$ & $34.00^{\mathrm{b}}$ \\
\hline $\mathrm{CmCa}$ & & $2.33^{\mathrm{ab}}$ & $4.83^{\mathrm{cd}}$ & $0.345^{\mathrm{c}}$ & $34.33^{\mathrm{b}}$ \\
\hline $\mathrm{CeCa}$ & & $2.50^{\mathrm{b}}$ & $5.06^{\mathrm{c}}$ & $0.359^{\mathrm{c}}$ & $33.33^{\mathrm{b}}$ \\
\hline $\mathrm{EcCeCm}$ & & $2.50^{\mathrm{b}}$ & $5.10^{\mathrm{c}}$ & $0.364^{\mathrm{c}}$ & $32.66^{\mathrm{b}}$ \\
\hline $\mathrm{EcCeCa}$ & & $2.43^{\mathrm{ab}}$ & $4.93^{\mathrm{cd}}$ & $0.352^{c}$ & $33.66^{\mathrm{b}}$ \\
\hline $\mathrm{CeCmCa}$ & & $2.20^{\mathrm{ab}}$ & $4.53^{\mathrm{cd}}$ & $0.323^{\mathrm{ac}}$ & $37.33^{\mathrm{a}}$ \\
\hline $\mathrm{EcCmCa}$ & & $2.40^{\mathrm{ab}}$ & $5.00^{\mathrm{c}}$ & $0.356^{c}$ & $33.66^{\mathrm{b}}$ \\
\hline $\mathrm{EcCeCmCa}$ & & $2.63^{b}$ & $5.40^{\mathrm{c}}$ & $0.385^{\mathrm{c}}$ & $31.00^{\mathrm{ab}}$ \\
\hline$\% \mathrm{CV}$ & & 18.08 & 15.27 & 15.24 & 12.04 \\
\hline
\end{tabular}

Key: Eucalpytus camaldulis (Ec), Catha edulis (Ce), Croton macrostachyus (Cm), Cordia africana (Ca); MRR=Mycelium Running Rate

Mean values within a column sharing the same superscript letter(s) are not significantly different by t-test with ( $\mathrm{P}>0.05)$; Less than $10 \% \mathrm{CV}$ indicates less variation in mean values of incubation periods. The smaller $\% \mathrm{CV}$ the less is the variation.

Maturation duration of oyster mushroom

The mean data recorded for different leaf litters composition for pinning to maturation showed no significant 
variation ( $\mathrm{p}>0.05)$. Most treatments took 3.66 - 4.33 days from pinning to maturation of fruit bodies (Figure $2 \mathrm{~d}$, e, $\mathrm{f}$ and Table 3).Between 3.66 and 4.33 days, the fruiting bodies became ready for harvest. Duration for the maturation of fruiting bodies after pinhead formation had no significance $(p>0.05)$ variations among different substrates and replicates.
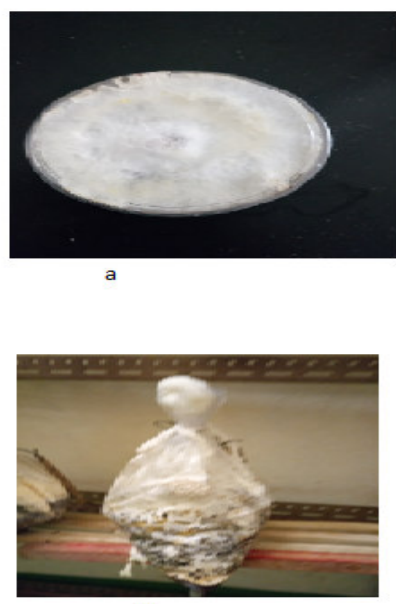
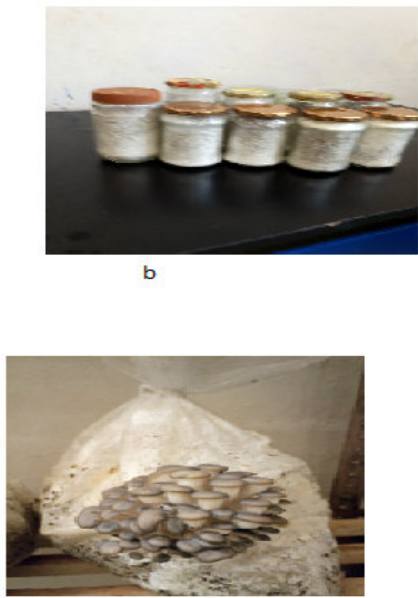
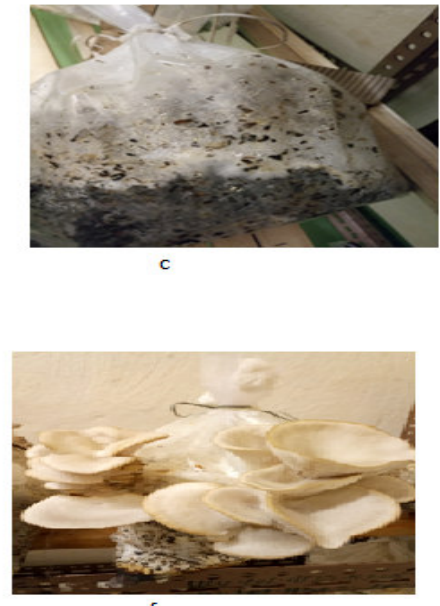

$f$

Figure 2. Progressive development of mushroom: (a) pure culture on PDA (b) oyster spawn ready for use (c) mycelia extension in main substrate $(\mathrm{d})$ primordia formed inside bags (e) elongating pinheads (f) mature oyster

Table 3. Period of pinning-to-maturation of mushrooms in substrates

\begin{tabular}{lllll}
\hline Leaf litters (substrates) & $1^{\text {st }}$ flush & $2^{\text {nd }}$ flush & $3^{\text {rd }}$ flush & $4^{\text {th }}$ flush \\
\hline $\mathrm{Ec}$ & $4.33^{\mathrm{a}}$ & $4.00^{\mathrm{a}}$ & $4.00^{\mathrm{a}}$ & $3.66^{\mathrm{ab}}$ \\
$\mathrm{Ce}$ & $4.00^{\mathrm{a}}$ & $4.00^{\mathrm{a}}$ & $3.66^{\mathrm{ab}}$ & $4.00^{\mathrm{a}}$ \\
$\mathrm{Cm}$ & $4.33^{\mathrm{a}}$ & $4.33^{\mathrm{a}}$ & $4.33^{\mathrm{a}}$ & $4.33^{\mathrm{a}}$ \\
$\mathrm{Ca}$ & $4.00^{\mathrm{a}}$ & $3.66^{\mathrm{ab}}$ & $4.00^{\mathrm{a}}$ & $3.66^{\mathrm{ab}}$ \\
$\mathrm{EcCe}$ & $4.33^{\mathrm{a}}$ & $4.33^{\mathrm{a}}$ & $4.33^{\mathrm{a}}$ & $4.00^{\mathrm{a}}$ \\
$\mathrm{EcCm}$ & $4.00^{\mathrm{a}}$ & $4.00^{\mathrm{a}}$ & $3.66^{\mathrm{ab}}$ & $3.66^{\mathrm{a}}$ \\
$\mathrm{EcCa}$ & $4.33^{\mathrm{a}}$ & $4.33^{\mathrm{a}}$ & $4.33^{\mathrm{a}}$ & $4.00^{\mathrm{a}}$ \\
$\mathrm{CeCm}$ & $4.33^{\mathrm{a}}$ & $4.33^{\mathrm{a}}$ & $4.00^{\mathrm{a}}$ & $4.00^{\mathrm{a}}$ \\
$\mathrm{CmCa}$ & $4.00^{\mathrm{a}}$ & $4.00^{\mathrm{a}}$ & $4.00^{\mathrm{a}}$ & $4.00^{\mathrm{a}}$ \\
$\mathrm{CeCa}$ & $4.33^{\mathrm{a}}$ & $4.33^{\mathrm{a}}$ & $4.00^{\mathrm{a}}$ & $4.00^{\mathrm{a}}$ \\
$\mathrm{EcCeCm}$ & $4.33^{\mathrm{a}}$ & $4.33^{\mathrm{a}}$ & $4.33^{\mathrm{a}}$ & $4.00^{\mathrm{a}}$ \\
$\mathrm{EcCeCa}$ & $4.00^{\mathrm{a}}$ & $4.00^{\mathrm{a}}$ & $4.00^{\mathrm{a}}$ & $4.00^{\mathrm{a}}$ \\
$\mathrm{CeCmCa}$ & $4.33^{\mathrm{a}}$ & $4.33^{\mathrm{a}}$ & $4.33^{\mathrm{a}}$ & $3.66^{\mathrm{ab}}$ \\
$\mathrm{EcCmCa}$ & $4.33^{\mathrm{a}}$ & $4.33^{\mathrm{a}}$ & $4.33^{\mathrm{a}}$ & $3.66^{\mathrm{ab}}$ \\
$\mathrm{EcCeCmCa}$ & $4.33^{\mathrm{a}}$ & $4.33^{\mathrm{a}}$ & $4.33^{\mathrm{a}}$ & $4.00^{\mathrm{a}}$ \\
$\% \mathrm{CV}$ & $3.81^{\mathrm{a} C \mathrm{C} C \mathrm{Ca}}$ & 5.10 & 5.88 & 5.12 \\
\hline $\mathrm{Key} E \mathrm{Ecalpytu}$
\end{tabular}

Key: Eucalpytus camaldulis (Ec), Catha edulis (Ce), Croton macrostachyus (Cm), Cordia africana (Ca)

Mean values within a column with the same superscript letter(s) are not significantly different ( $p>0.05)$. CV for the mean values is less than $10 \%$ showing there is no significant variation of mean values.

Yield of mushroom per flush (wet weight) showed significant $(\mathrm{p}<0.05)$ variation between treatments with application of different leaf litters combinations except the total yield (Table 4) as well as between flushes. Croton macrostachyus $(\mathrm{Cm})$ leaf litters showed the highest fresh weight $(245.79 \mathrm{~g})$ in first flush followed by Eucalpytus camaldulis (Ec) (245.39 g) leaf litters, while combination of Eucalpytus camaldulis and Croton macrostachyus $(\mathrm{EcCm})$ was found to be the least $(157.45 \mathrm{~g})$ in the first flushing. In the second flush, the highest yield $(124.73 \mathrm{~g})$ was obtained from a combination of Eucalpytus camaldulis $(\mathrm{Ec})$ and Croton macrostachyus $(\mathrm{Cm})$ leaf litters. Eucalpytus camaldulis (Ec) was found to be the least $(65.06 \mathrm{~g})$ in the second flush. In third flush, leaf litters of Croton macrostachyus $(\mathrm{Cm})$ gave the highest yield $(35.64 \mathrm{~g})$ followed by combination of Eucalpytus camaldulis, Catha edulis, Croton macrostachyus and Cordia africana (EcCeCmCa) (32.61g). Nevertheless, the yield obtained from the remaining treatments was more or less small. Relatively, compared to all the flushes, lowest yield of mushroom was obtained in the $4^{\text {th }}$ flush. Yield per flush of leaf litters showed significant $(p>0.05)$ variations in all flushes. Specially, high yield per flush of the substrate was observed in the first flush, while the lowest yield per flush was observed from the $4^{\text {th }}$ flush. 
Table 4. Mean yield per flush per $400 \mathrm{~g}$ (dry weight) substrate

\begin{tabular}{lllll}
\hline Leaf litters ( substrates) & $1^{\text {st }}$ flush & $2^{\text {nd }}$ flush & $3^{\text {rd }}$ flush & $4^{\text {th }}$ flush \\
\hline $\mathrm{Ec}$ & $4.33^{\mathrm{a}}$ & $4.00^{\mathrm{a}}$ & $4.00^{\mathrm{a}}$ & $3.66^{\mathrm{ab}}$ \\
$\mathrm{Ce}$ & $4.00^{\mathrm{a}}$ & $4.00^{\mathrm{a}}$ & $3.66^{\mathrm{ab}}$ & $4.00^{\mathrm{a}}$ \\
$\mathrm{Cm}$ & $4.33^{\mathrm{a}}$ & $4.33^{\mathrm{a}}$ & $4.33^{\mathrm{a}}$ & $4.33^{\mathrm{a}}$ \\
$\mathrm{Ca}$ & $4.00^{\mathrm{a}}$ & $3.66^{\mathrm{ab}}$ & $4.00^{\mathrm{a}}$ & $3.66^{\mathrm{ab}}$ \\
$\mathrm{EcCe}$ & $4.33^{\mathrm{a}}$ & $4.33^{\mathrm{a}}$ & $4.33^{\mathrm{a}}$ & $4.00^{\mathrm{a}}$ \\
$\mathrm{EcCm}$ & $4.00^{\mathrm{a}}$ & $4.00^{\mathrm{a}}$ & $3.66^{\mathrm{ab}}$ & $3.66^{\mathrm{a}}$ \\
$\mathrm{EcCa}$ & $4.33^{\mathrm{a}}$ & $4.33^{\mathrm{a}}$ & $4.33^{\mathrm{a}}$ & $4.00^{\mathrm{a}}$ \\
$\mathrm{CeCm}$ & $4.33^{\mathrm{a}}$ & $4.33^{\mathrm{a}}$ & $4.00^{\mathrm{a}}$ & $4.00^{\mathrm{a}}$ \\
$\mathrm{CmCa}$ & $4.00^{\mathrm{a}}$ & $4.00^{\mathrm{a}}$ & $4.00^{\mathrm{a}}$ & $4.00^{\mathrm{a}}$ \\
$\mathrm{CeCa}$ & $4.33^{\mathrm{a}}$ & $4.33^{\mathrm{a}}$ & $4.00^{\mathrm{a}}$ & $4.00^{\mathrm{a}}$ \\
$\mathrm{EcCeCm}$ & $4.33^{\mathrm{a}}$ & $4.33^{\mathrm{a}}$ & $4.33^{\mathrm{a}}$ & $4.00^{\mathrm{a}}$ \\
$\mathrm{EcCeCa}$ & $4.00^{\mathrm{a}}$ & $4.00^{\mathrm{a}}$ & $4.00^{\mathrm{a}}$ & $4.00^{\mathrm{a}}$ \\
$\mathrm{CeCmCa}$ & $4.33^{\mathrm{a}}$ & $4.33^{\mathrm{a}}$ & $4.33^{\mathrm{a}}$ & $3.66^{\mathrm{ab}}$ \\
$\mathrm{EcCmCa}$ & $4.33^{\mathrm{a}}$ & $4.33^{\mathrm{a}}$ & $4.33^{\mathrm{a}}$ & $3.66^{\mathrm{ab}}$ \\
$\mathrm{EcCeCmCa}$ & $4.33^{\mathrm{a}}$ & $4.33^{\mathrm{a}}$ & $4.33^{\mathrm{a}}$ & $4.00^{\mathrm{a}}$ \\
$\% \mathrm{CV}$ & $3.81^{\mathrm{a} C \mathrm{Ca}}$ & 5.10 & 5.88 & 5.12 \\
\hline
\end{tabular}

Key: Eucalpytus camaldulis (Ec), Catha edulis (Ce), Croton macrostachyus (Cm), Cordia africana (Ca)

Mean values within a column with the same superscript letter(s) are not significantly different ( $p>0.05)$.

The highest number of fruiting bodies was collected from leaf litters of Croton macrostachyus (Cm) (26.99), while a combination of Eucalpytus camaldulis, Catha edulis and Croton macrostachyus (EcCeCm) as well as the combination of Eucalpytus camaldulis, Croton macrostachyus and Cordia africana (EcCmCa) gave the least number of fruiting bodies (23.99) (Table 5). Pileus diameter was found maximum for the samples collected from leaf litters composed of Eucalpytus camaldulis and Croton macrostachyus $(\mathrm{EcCm})(5.03 \mathrm{~cm})$ but minimum for the sample collected from combination of Catha edulis and Croton macrostachyus $(\mathrm{CeCm})(4.77 \mathrm{~cm})$ with no significant $(\mathrm{p}>0.05)$ variation. The shortest stipe length of oyster mushroom was observed in combination of Eucalpytus camaldulis and Croton macrostachyus $(\mathrm{EcCm})(1.98 \mathrm{~cm})$ and the longest stipe length seen in Catha edulis $(\mathrm{Ce})$ and a combination of Eucalpytus camaldulis, Catha edulis and Croton macrostachyus $(\mathrm{EcCeCm})$ $(2.16 \mathrm{~cm})$. The stipe length of all the samples did not show significant variation among the different treatments. The highest total wet/fresh weight of mature mushroom was recorded from leaf litters of Croton macrostachyus $(\mathrm{Cm})(377.83 \mathrm{~g})$ and the least total fresh/wet weight was recorded from combination of Eucalpytus camaldulis and Catha edulis (EcCe) (323.60 g).

Table 5. Effect of leaf litters on yield parameters of mushrooms

\begin{tabular}{|c|c|c|c|c|}
\hline \multirow{2}{*}{$\begin{array}{l}\text { Leaf litters } \\
\text { (substrates) }\end{array}$} & \multicolumn{2}{|c|}{ Mean yield measures $/ 400 \mathrm{~g}$ substrate } & \multirow[t]{2}{*}{ № of matures } & \multirow[t]{2}{*}{$\mathrm{W} / \mathrm{t}$ of mature } \\
\hline & Pileus diameter $(\mathrm{cm})$ & Stipe length $(\mathrm{cm})$ & & \\
\hline $\mathrm{Ec}$ & $4.83^{\mathrm{a}}$ & $2.12^{\mathrm{a}}$ & $24.65^{\mathrm{ab}}$ & $358.89^{\mathrm{b}}$ \\
\hline $\mathrm{Ce}$ & $4.78^{\mathrm{a}}$ & $2.16^{\mathrm{a}}$ & $25.32^{\mathrm{a}}$ & $356.59^{\mathrm{ab}}$ \\
\hline $\mathrm{Cm}$ & $4.82^{\mathrm{a}}$ & $2.14^{\mathrm{a}}$ & $26.99^{\mathrm{a}}$ & $377.83^{\mathrm{a}}$ \\
\hline $\mathrm{Ca}$ & $5.01^{\mathrm{a}}$ & $2.06^{\mathrm{a}}$ & $24.98^{\mathrm{ab}}$ & $326.03^{\mathrm{d}}$ \\
\hline $\mathrm{EcCe}$ & $4.95^{\mathrm{a}}$ & $2.06^{\mathrm{a}}$ & $24.99^{\mathrm{ab}}$ & $323.60^{\mathrm{d}}$ \\
\hline $\mathrm{EcCm}$ & $5.03^{\mathrm{a}}$ & $1.98^{\mathrm{a}}$ & $24.99^{\mathrm{ab}}$ & $327.63^{\mathrm{bc}}$ \\
\hline $\mathrm{EcCa}$ & $4.85^{\mathrm{a}}$ & $2.08^{\mathrm{a}}$ & $24.98^{\mathrm{ab}}$ & $330.96^{\mathrm{bc}}$ \\
\hline $\mathrm{CeCm}$ & $4.77^{\mathrm{a}}$ & $2.14^{\mathrm{a}}$ & $24.66^{\mathrm{ab}}$ & $340.53^{c}$ \\
\hline $\mathrm{CmCa}$ & $4.81^{\mathrm{a}}$ & $2.11^{\mathrm{a}}$ & $25.32^{\mathrm{a}}$ & $346.42^{c}$ \\
\hline $\mathrm{CeCa}$ & $4.98^{a}$ & $2.03^{\mathrm{a}}$ & $24.65^{\mathrm{a}}$ & $326.88^{d}$ \\
\hline $\mathrm{EcCeCm}$ & $4.80^{\mathrm{a}}$ & $2.16^{\mathrm{a}}$ & $23.99^{\mathrm{ab}}$ & $335.53^{\mathrm{bc}}$ \\
\hline $\mathrm{EcCeCa}$ & $4.93^{\mathrm{a}}$ & $2.05^{\mathrm{a}}$ & $24.32^{\mathrm{ab}}$ & $336.73^{b c}$ \\
\hline $\mathrm{CeCmCa}$ & $4.95^{\mathrm{a}}$ & $2.01^{\mathrm{a}}$ & $24.32^{\mathrm{ab}}$ & $331.42^{\mathrm{bc}}$ \\
\hline $\mathrm{EcCmCa}$ & $4.98^{a}$ & $2.04^{\mathrm{a}}$ & $23.99^{\mathrm{ab}}$ & $331.58^{\mathrm{bc}}$ \\
\hline $\mathrm{EcCeCmCa}$ & $4.91^{\mathrm{a}}$ & $2.04^{\mathrm{a}}$ & $24.66^{\mathrm{ab}}$ & $331.14^{\mathrm{bc}}$ \\
\hline$\% \mathrm{CV}$ & 1.81 & 2.72 & 2.90 & 4.47 \\
\hline
\end{tabular}

Key: Eucalpytus camaldulis (Ec), Catha edulis (Ce), Croton macrostachyus (Cm), Cordia africana (Ca)

Mean values within a column sharing the same superscript letter(s) are not significantly different by LSD test with $(P>0.05) . \% C V$ of mean values shows the variation is insignificant.

Biological efficiency of different locally available leaf litters of the study area were tested against total mushroom productivity and the result showed that highest biological efficiency was recorded with leaf liters of Croton macrostachyus $(\mathrm{Cm})$, followed by Catha edulis $(\mathrm{Ce})$. The least was recorded with the leaf litters of 
combination of Eucalpytus camaldulis and Croton macrostachyus (EcCm) but there was no significance variation between the rests.

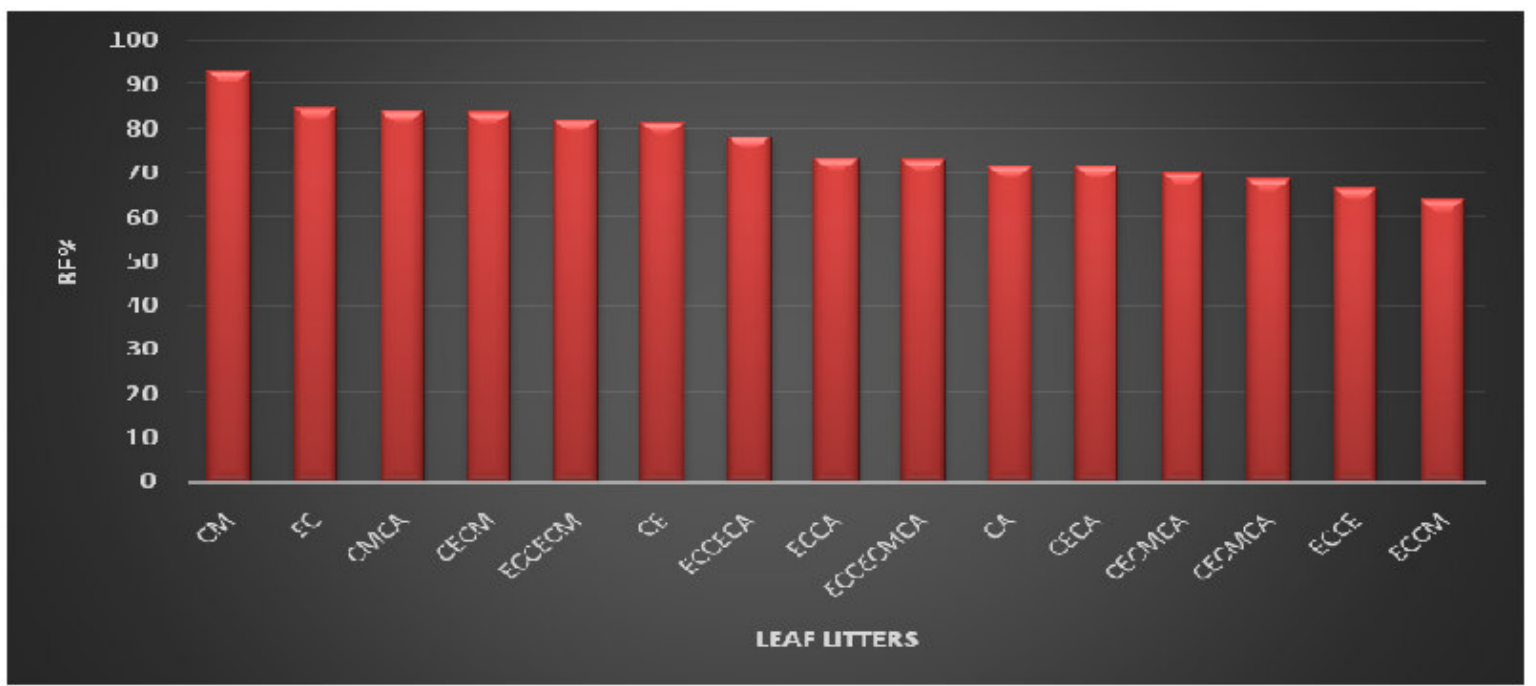

Figure 3. Biological efficiency of the oyster mushrooms grown on different leaf litters Key: Eucalpytus camaldulis (Ec), Catha edulis (Ce), Croton macrostachyus (Cm), Cordia africana (Ca)

\section{Discussion}

Cultivation technology of edible mushroom is very common practice worldwide as it is one of the forthcoming technologies, but in Ethiopia this technology is on infant stage. In the present study the length of complete mycelia invasion in the substrate bags were measured at 23 to 37.33 days. Similarly, Keneni and Kebede (2017) reported that the total days required for complete colonization of substrate in all treatments was 15 days, which is by far less than the present study which required longer days for complete colonization of the leaf litters. According to Gume et al. (2013) complete mycelial invasion occurred in the range of 17-23 days, which not in line with the present study. In general compared to researches reported by Keneni and Kebede (2014), Keneni and Kebede (2017), Gume et al. (2013) and Haileselassie and Teklay (2014). The present study indicated that slower mycelial run and longer time taken for complete colonization. This is may be due to lack of or shortage of easily assimilated carbohydrates, since same variety of leaf litters may not store soluble sugars and may be due to the cooler temperature during the experiment.

Almost all leaf litters with faster mycelia extension produced higher yields, there is also significant variation among leaf litters in mycelial extension and therefore, it may be possible to construe the faster mycelia invasion as indicative of the higher yield. Regarding incubation period, Catha edulis gave the shorter incubation periods (34.66 days) on average and the combination of Croton macrostachyus and Cordia africana leaf litters gave the longest incubation periods (47.00 days) to the $1^{\text {st }}$ inoculation to flush.

In this study, the incubation period taken from the $1^{\text {st }}$ to $2^{\text {nd }}$ flush, $2^{\text {nd }}$ to $3^{\text {rd }}$ flush and $3^{\text {rd }}$ to the $4^{\text {th }}$ flush occurred in shorter times in general and there was no significance difference between each treatment. The incubation period taken from the $1^{\text {st }}$ flush to the $2^{\text {nd }}$ flushes, from $2^{\text {nd }}$ to $3^{\text {rd }}$ and from $3^{\text {rd }}$ to $4^{\text {th }}$ flushes followed similar trends except inoculation to the first flush which resulted in the highest mean duration of time required for the completion of oyster mushroom. Incubation periods between flushes of the current study took longer days than that of Gume et al. (2013) except between the first and the second flush. They reported that the mean duration of incubation between the first and second flushes was 12 days where $12 \pm 6.3$ days recorded. It took $7.6 \pm 2.3$ days for substrates to incubate from the second to the third flushes and $6.4 \pm 2.5$ from third to fourth flushes, which took slightly shorter days than the present study. This is most probably due to the cooler temperature during the conduction of the experiment of the current study. Longer days of incubation from flush to flush of oyster mushroom in the present study was 10.66 on average while the shorter days was 9.33 days on average for all four flushes and all flushes followed the same trend. There is no significant variation among incubation periods between different flushes.

Duration for the maturation of fruit bodies after pinhead formation had no significance variations among different substrates and replicates it took 3.66 to 4.33 days in most cases. However, Gume et al. (2013) has obtained the period of pinning-to-maturation of Pleurotus ostreatus mushrooms, the shortest mean duration was 3.3 days and the longest was 6.0 days throughout the treatment substrates and flushes.

Regarding yield of mushroom per flush, in the first flush Croton macrostachyus leaf litters gave the highest fresh weight of $245.79 \mathrm{~g}$ per $400 \mathrm{~g}$ followed by Eucalyptus camaldulensis leaf litters $245.39 \mathrm{~g}$ per $400 \mathrm{~g}$, while 
combination of Eucalyptus camaldulensis and Croton macrostachyus leaf litters gave $157.45 \mathrm{~g}$ per $400 \mathrm{~g}$, found to be the least. From this investigation, in all the treatments comparable yield of mushroom were obtained in $3^{\text {rd }}$ and $4^{\text {th }}$ flushes. Generally yield decreases as flush number increases. This observation was greater than the report of Gume et al.(2013) and less than that of Keneni and kebede (2017) in BE.

Concerning the effects of leaf litters on yield parameters of mushroom, the lowest and highest pileus diameter was obtained from a combination of Catha edulis and Croton macrostachyus and from a combination of Eucalyptus camaldulensis and Croton macrostachyus ( $4.77 \mathrm{~cm}$ and $5.03 \mathrm{~cm}$ ), respectively.Kimenju et al., (2009) reported slightly different results from sugarcane bagasse $(4.8 \mathrm{~cm})$ and saw dust $(3.4 \mathrm{~cm})$. This result is also slightly differ from Gume et al., (2013), who reported mean pileus diameter of mushrooms that ranged from 3.8 to $5.2 \mathrm{~cm}$ and slightly lower than report of Keneni and Kebede,(2017), who reported the pileus diameter ranging from 6.5 to $8.7 \mathrm{~cm}$.

Generally, substrates with lower yield gave mature oyster mushrooms with shorter mean stipe length, longer pileus diameter and less number of mature mushrooms. The opposite was true in case of mushrooms from substrates of higher yield. However, the mean differences of pileus diameters and stipe lengths of mushrooms obtained from different treatment substrates were insignificant. This contradicts the result observed by Kimenju et al. (2009) in which both of the parameters were significantly affected by different substrates.

In this study, the highest BE was recorded from Croton macrostachyus (94.45\%) and the lowest was from a combination of Eucalpytus camaldulis and Catha edulis $(80.90 \%)$ respectively. The total yields of pure substrates such Croton macrostachyus gave relatively higher yields than other alone or combination with others. Eucalpytus camaldulis and Croton macrostachyus gave the highest yield when not combined but gave almost the least yield when combined, which is to the opposite of Gume et al. (2013) who reported that Sawdust of Cordia africana gave the least percentage of BE $(29.07 \%)$ whereas combination from the four substrates, of saw dust of Cordia africanas, saw dust of kerero, corn cobs and coffee been husks showed the highest BE (77.38\%). In general the biological efficiency of the present study is in the ranges of other researchers report. Alam et al. (2007) have observed that the biological efficiency ranged from 45.21 to $125.70 \%$ in the case of oyster mushroom. Shimelis, A. (2011) reported that high biological efficiency $(98.57 \%)$ was obtained from aerobic composted coffee husk when it was supplemented with $10 \%$ wheat bran, $8 \%$ chicken manure and $2 \%$ ash. Concerning BE, what was observed in the present study is not far from previous report though there were no such additional nutrients done.

\section{Conclusion}

All leaf litters treated in this study gave high yields of Pleurotus ostreatus which indicated the possibility of oyster mushroom cultivation on the locally available leaf litters which are simply wasted in environment. Also, different leaf litters treated in this study showed the possibility and suitability for cultivation of Pleurotus ostreatus with relatively high biological efficiency Croton macrostachyus produced $94.45 \%$ and combination of Eucalyptus camaldulensis and Catha edulis produced $80.09 \%$. All the other leaf litters were produced a BE between $80.90 \%$ and $94.45 \%$

\section{Competing interests}

The authors declare that they have no competing interests regarding the publication of this manuscript.

\section{Author's contributions}

TG and DM conceptualized the idea and drafted the initial proposal. TG was finalized the study proposal.TG contributed to data processing and analysis. MD drafted the manuscript.

\section{Acknowledgements}

I would like to thank Addis Ababa University for offering all the financial expenses. I am greatly indebted to Department of Biology, Wollega University, for the provision of Laboratory material and other facilities.

\section{Author details}

${ }^{1}$ Msc. In Biology, Nekemte Preparatory School, Nekemte, Ethiopia

${ }^{2}$ PhD-Departments of Microbial, Cellular and Molecular Biology, Addis Ababa University, Post Bo No: 1176, Addis Ababa, Ethiopia:

3* PhD-Department of Biology, Wollega University, Post Box No: 395, Nekemte, Ethiopia

\section{References}

Abate, D. (1998). Mushroom cultivation: A practical approach. Berhanena Selam printing press. Addis Ababa. pp. 17-72.

Alam,N.,Khan,A.,Hossan,M.S.,Amin S.M.R. and Khan,L.A.(2007).Nutritional analysis of dietary mushroom Pleurotus florida Eger and P.sajorcoj (Fr.) Signer. Bangladesh Journal of mushroom, 1: 1-7

Alemu, F. (2014). Cultivation of oyster mushroom (Pleurotus ostreatus) on teff straw (by-product of agriculture) at Dilla. Global Advanced Research Journal of medicine and medical Sciences, 3: 205-215.

Badshah, N., Ur-Rehman, N. and Wahid, M. (1992). Yield and quality of mushrooms grown on different substrates. 
Sarhad Journal of Agriculture, 8: 631-63.

Beteez, A. and Kustudia, M., (2004). Mushroom cultivation and marketing horticulture production. ATTRA publication. pp: 1-25.

Chang, S.T. and Miles,P.G. (2004). The cultivation and nutritional value of Pleurotus sajor caju. European Journal of Applied Microbiology, 12: 58-62.

Feeney, M.J. and Beelman, R. (2004). Mushrooms in a class of their own. Sindh Agriculture university, tandojam printing press. pp: 37.

Gume,B.,Mulata,D. and Abate,D. (2013).Evaluation of locally available substrates for cultivation of oyster mushroom (Pleurotus ostreatus) in Jimma, Ethiopia. African Journal of Microbiology Research, 7: 22282237.

Haileselassie, M. and Teklay,S. (2014). Suitability of locally available substrates for oyster mushrooms cultivation in Mekelle City, Tigray, Ethiopia. Sky Journal of Food Science, 3: 47-51

Imtiaj, A and Rahman, S.A. (2008). Economic viability of mushroom cultivation to poverty reduction in Bangladidesh. Tropical and Subtropical Agroecosystems, 8:93-99.

Iqbal, S.M., Rauf, C.A., and Sheikh, M.I. (2005). Yield performance of Oyster Mushroom on different substrates. International. Journal of Agricultural Biology, 7: 900-903.

Keneni,A. and Kebede,G. (2014). Cultivation of oyster mushroom (Pleurotus ostreatus) on Substratum Composed of Waste Paper and Cotton Seed Wastes. Advanced Journal of Agricultural Research, 2: 114-122.

Keneni,A. and Kebede,G. (2017). Growth and yield of oyster mushroom (Pleurotus ostreatus) on substrate composed from different proportion of maize (Zea mays L.) leaves and sheath and cotton seed waste. $A n$ international peer reviewed multidisciplinary science journal.6:1-15

Kimenju, J.W., Odero, O.M., Mutitu, E.W., Wachra, P.M., Narla, R.D. and Muiru, W.M. (2009). Suitability of locally available substrates for oyster mushroom (Pleurotus ostreatus) cultivation in Kenya. Asian Journal of Plant Science, 8: 510-514.

Kivaisi, A.K. (2007). Mushroom cultivation in Tanzania. Amelia KajumuloKivaisi, Dar es Salam. Website, www.MushWorld.com

Mush World (2004). Mushroom growers' handbook 1: Oyster mushroom cultivation.

Oei, P. (2005). Small-scale mushroom cultivation: oyster, shiitake and wood ear mushrooms. Agromisa foundation and CTA, Netherlands

Onuoha, C.I., Uchechi U. and Onuoha. B.C. (2009). Cultivation of Pleurotus pulmonarius (Mushroom) Using Some Agrowaste Materials. Agricultural Journal, 4: 109-112.

Peng, J.T., Lee, C.M., and Tsai, Y.F. (2000). Effect of Rice bran on the production of different king oyster mushroom strains during bottle cultivation. Journal of Agricultural Research, 49: 60-67.

Rajapakse, J.C., Rubasingha, P. and Dissanayake, N.N.(20O7). The effect of six substrates on the growth and yield of American oyster mushrooms based on jancao technology. The Journal of Agricultural Science, 3: 82-85.

Shimelis, A. (2011).Optimization of Coffee Wastes for the Cultivation of Pleurotus Ostreatus. A Thesis Submitted to the School of Graduate Studies of Addis Ababa University in Partial fulfilments for the Degree of Master of Science in biology (Unpublished).

Singh, R. and Singh, U. C. (2005). Modern Mushroom Cultivation. Jodhpur: Updesh Purohit for Agrobios. 